\title{
The "Wicked" Nature of the Herbicide Resistance Problem
}

\author{
David R. Shaw*
}

\begin{abstract}
Sociologists define a wicked problem as one without clear causes or solutions, and thus difficult or impossible to solve. Herbicide resistance is the epitome of a wicked problem: the causes are convoluted by myriad biological and technological factors, and are fundamentally driven by the vagaries of human decision-making. Weed scientists for decades have conducted research and developed educational programs to prevent or mitigate evolution of herbicide resistance, yet resistance is more prevalent today than ever before. If we expect to achieve success in herbicide resistance management, different approaches will be essential. The second Herbicide Resistance Summit focused on "doing something different," bringing in rural sociologists, agricultural economists, weed scientists, and crop consultants to discuss the decision-making process itself, community-based approaches to resistance management, economics of resistance management, potential regulatory and incentive programs, new approaches to educational programs, diversification of weed management, and a call to action for everyone involved in the decisionmaking process.
\end{abstract}

Key words: Herbicide Resistance Summit, herbicide resistance, wicked problem.

Herbicide resistance is far from a new topic; reports of the evolution of resistance go back as early as the 1950s (Switzer 1957). Since this first reported incidence, weed managers have often been on a continuous treadmill of using a herbicide mechanism of action (MOA) until it is no longer effective, then replacing it with another MOA in the same way when research and development brings it to market. Figure 1 depicts the unique instances of herbicide resistance cases since the first report in 1957. Resistance has increased rapidly since 1975 , and has now surpassed 450 species by herbicide MOA combinations (Heap 2015).

While the current public discourse regarding resistance to the herbicide glyphosate has portrayed it as a unique event, in actuality it is only another step in the continuing cycle of resistance development. In fact, the introduction of glyphosateresistant crops (GRCs) came at a time in which they were viewed as a salvation from the exploding problem of weeds resistant to the acetolactate synthase (ALS)-inhibiting herbicides in the 1990s. What is unique about the emergence of glyphosate resistance is the severity of selection pressure for herbicide resistance that was placed on agronomic production by rapid adoption of GRCs throughout the entire United States and worldwide. More than

\footnotetext{
DOI: $10.1614 /$ WS-D-15-00035.1

* Giles Distinguished Professor of Weed Science, Department of Plant and Soil Sciences, Mississippi State University, Mississippi State, MS 39762. Corresponding author’s E-mail: dshaw@research.msstate.edu
}

90\% of U.S. soybean [Glycine $\max$ (L.) Merr.], corn (Zea mays L.), cotton (Gossypium hirsutum L.), and sugarbeet (Beta vulgaris L.) acreage is planted to GRCs, and in many instances multiple applications of glyphosate alone are made every year on these crops. When GRCs were first released, many if not most weed scientists thought that the unique MOA of glyphosate would make it highly unlikely that weeds would evolve resistance (e.g., Bradshaw et al. 1997). Weed biologists now understand that the selection pressure placed on production systems when millions of hectares are managed using one MOA continuously over many years made glyphosate resistance evolution inevitable. This has been highlighted by the emergence of glyphosate-resistant Palmer amaranth (Amaranthus palmeri S. Wats.) as an extraordinarily challenging weed in the southern United States. As an example of the severity of this problem, Figure 2 shows Palmer amaranth in cotton after treatment with multiple applications of glyphosate.

With the current focus on glyphosate resistance, public impression is that it is one of the few herbicides for which resistance has developed. This could not be further from the truth. Figure 3 shows the number of species exhibiting resistance to five different classes of herbicides. Glyphosate, a 5enolpyruvylshikimate-3-phosphate (EPSP) synthase inhibitor, has far fewer species with evolved resistance than several other herbicide MOAs. Of particular note is the prevalence of resistance to ALS-inhibiting herbicides, with over 140 species 


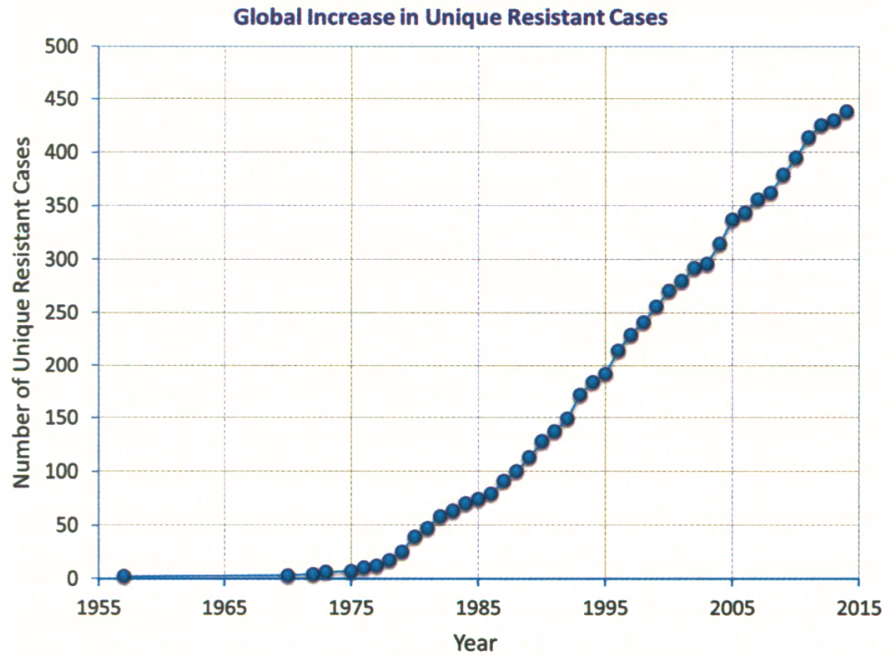

Figure 1. The chronological increase in unique cases of herbicide resistant weeds worldwide. From http://www.weedscience.org.

having confirmed resistance to this class of chemistry.

Probably one of the most alarming data sets related to herbicide resistance is contained in Figure 4. As a species develops resistance to more than one MOA, the number of options for effective control from herbicides is reduced. In addition, incidences of metabolic resistance to multiple MOAs have been reported in several species, which is of grave concern because this will impart the ability to rapidly evolve resistance to herbicides with other MOAs. Rigid ryegrass (Lolium rigidum Gaudin) has the dubious distinction of leading all species currently, with confirmed resistance to 12 distinct MOAs.

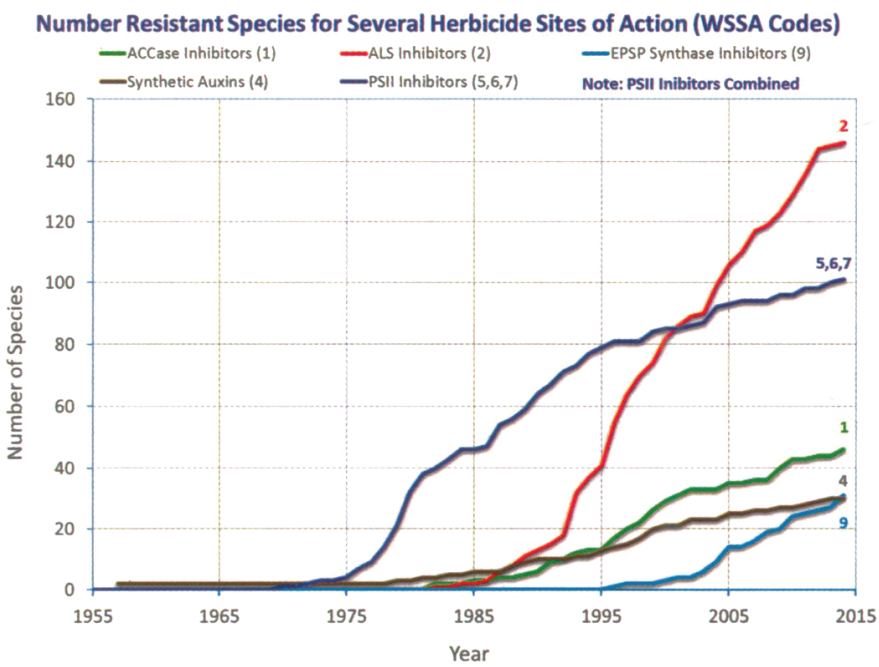

Figure 2. The chronological increase in resistance to five herbicide sites of action. From http://www.weedscience.org.

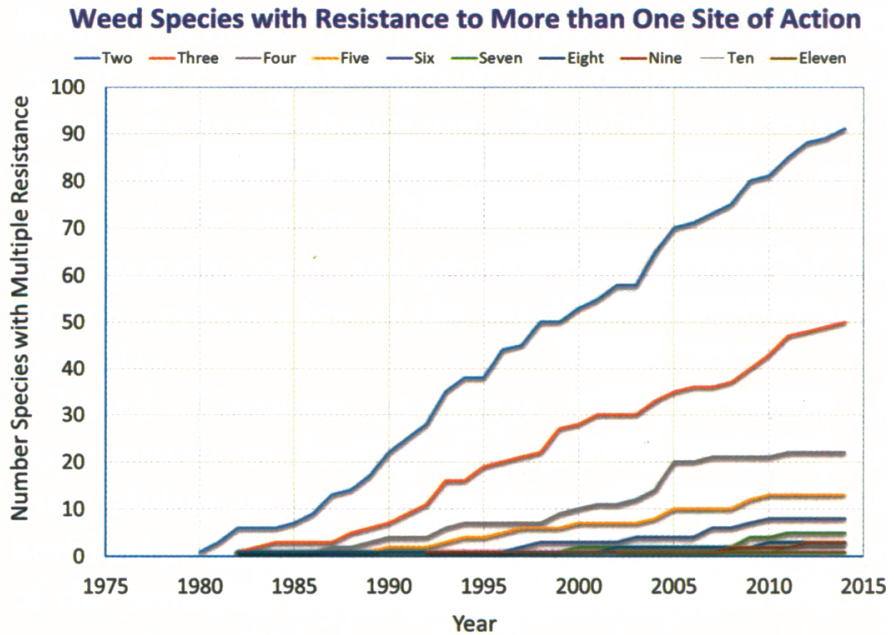

Figure 3. The number of weed species with demonstrated resistance to more than one herbicide mechanism of action. From http://www.weedscience.org.

General perception is also that herbicide resistance is primarily a corn-soybean-cotton problem. Figure 5 clearly dispels that myth, with more resistant weed species occurring in wheat (Triticum aestivum $\mathrm{L}$.) than any other crop. As already noted, resistance is most likely to evolve whenever a single MOA is used repeatedly without a sound stewardship approach to diversify the weed management program. In each crop depicted in Figure 5, resistance occurred when community-influencing decisions regarding weed management did not effectively promote diversification of weed management strategies.

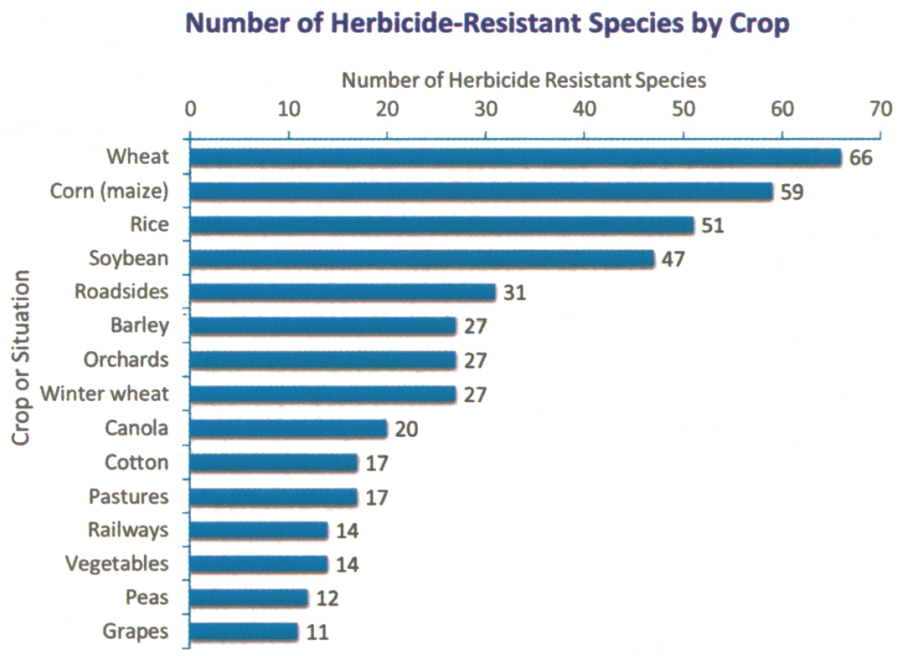

Figure 4. The number of weed species resistant to herbicides in various crops and land-use situations. From http://www. weedscience.org.

Shaw: Wicked nature of herbicide resistance -553 
Number of Herbicide Resistant Weed Species by Weed Family (Top 10)

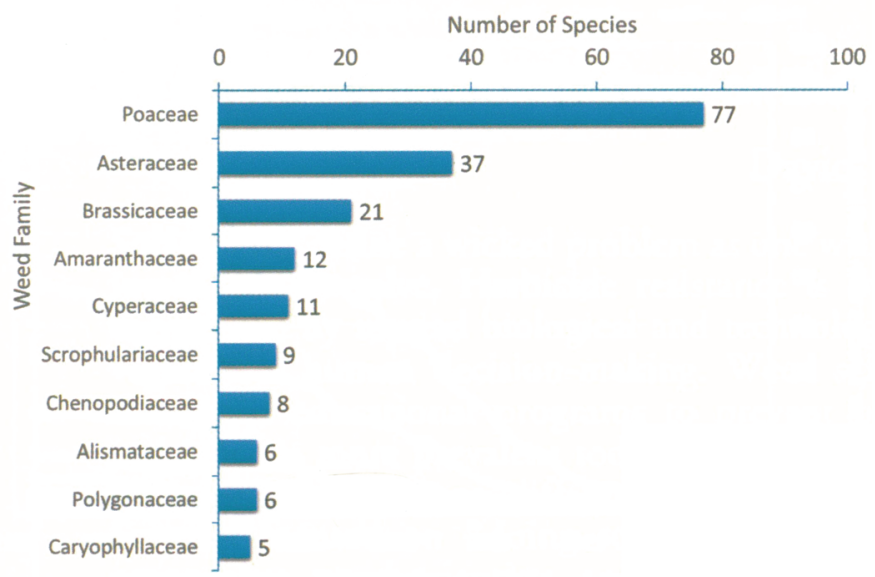

Figure 5. The number of herbicide-resistant weed species within the top 10 plant families. From http://www.weedscience.org.

In addition to misperceptions about the extent of the herbicide resistance problem, there is often poor understanding about the breadth and depth of the issue. Most of the press recently has focused on weedy species in the Amaranthus family such as Palmer amaranth and common waterhemp. However, Figure 5 clarifies the extent of the problem, with members of the grass and aster families dwarfing other plant families in incidences of resistance. That is not to say that the Amaranthus family is not an issue; rather, it is to point out that the problem of herbicide resistance goes far beyond a few species or a few crops.

Weed scientists in general, and the Weed Science Society of America (WSSA) specifically, have not been ignoring this issue. In the mid2000s, two Glyphosate Stewardship Forums were held, bringing industry and academia together to discuss the threat of glyphosate resistance. A number of symposia have been conducted at annual WSSA meetings for the last several decades. A report was developed by the National Research Council on the use of genetically modified (GM) crops, and a part of that report specifically addressed the threat of herbicide resistance evolution because of overuse of the technology. Extension weed specialists have developed thousands of publications, presentations, and training materials on herbicide resistance prevention and mitigation. The WSSA developed a series of training modules for agronomic crops, turfgrass, noncropland, and aquatic habitats that specifically addressed herbicide resistance management. The Council for
Agricultural Science and Technology commissioned a special report on the impact of herbicide resistance on soil conservation practices. Research on weed biology, physiology, and field management systems has been conducted in the United States and globally.

The U.S. Department of Agriculture (USDA)Animal Plant Health Inspection Service (APHIS) commissioned WSSA to provide a complete review of the literature associated with herbicide resistance, as the agency grappled with how to best understand their role in preventing the evolution of herbicide resistance during and following certification of GM crops with herbicide resistance traits (Vencill et al. 2012). The APHIS also commissioned a second report from WSSA, focusing on the identification of best management practices (BMPs), barriers to implementing these BMPs, and recommendations to overcome these barriers (Norsworthy et al. 2012). A special issue of Weed Science was published that contained these reports (available at http://wssajournals.org/toc/ wees/60/sp 1$)$.

The WSSA worked with the National Academy of Science to conduct the first Herbicide Resistance Summit in 2012 to review the BMPs, discuss the obstacles to their implementation, and present the recommendations from the APHIS-commissioned report to Summit participants (information on the Summit can be found at http://nas-sites.org/hrweeds-summit/).

\section{And Yet. With All of this Information, All of this Focus, All of this Attention, the Problem of Herbicide Resistance Continues to Increase Exponentially}

Sociologists refer to a problem with no simple causes or solutions as a "wicked" problem, a term originated from a lecture by Horst Rittel in 1967. Churchman (1967) expanded on the discussion from Rittel and Webber, stating "wicked problems refer to that class of social system problems which are ill-formulated, where the information is confusing, where there are many clients and decision makers with conflicting values, and where the ramifications in the whole system are thoroughly confusing. The adjective 'wicked' is supposed to describe the mischievous and even evil quality of these problems, where proposed 'solutions' turn out to be worse than the symptoms." Characteristics of 
a wicked problem include (adapted from Rittel and Webber, 1973):

- No definitive formulation

- No final solution

- No true/false or good/bad answers

- No definitive solution set

- Every wicked problem unique

- Multiple potential and viable causes

- Intolerance for ineffective solutions

Herbicide resistance is the epitome of a wicked problem. Following are but a few of the many factors that contribute to this wicked problem.

First: There are a number of biological and technological drivers in the evolution of herbicide resistance. The types of resistance vary widely, from target-site mutation to metabolic resistance. A variety of biological approaches to resistance have occurred, and often have been very difficult to predict. As noted earlier, for example, there were a number of reasons why scientists doubted that resistance to glyphosate would ever develop. Similarly, when the ALS herbicides were developed, they were first viewed as the epitome of a success story in herbicide discovery, only to find that targetsite mutations were widely prevalent in a number of weed species. Resistance to this class of chemistry was so widespread in the late 1990 s that the development of GRCs was viewed as a salvation for crop production by many. Although companies have massive development and screening programs, chance discoveries are the norm rather than the exception. Companies rightly, from a business perspective, invest heavily in exploring new chemical variants of compounds with known MOAs to expand into new crop markets, weed species controlled, or application methods and timing. While this makes perfectly good sense from a technology and business sense, it is a key challenge from a herbicide resistance perspective, given the additional selection pressure placed on the ecological system as a whole.

Second: The human decision-making process is the key driver behind resistance evolution. While we are dealing with an evolutionary phenomenon in response to technological developments, at its core herbicide resistance evolution is a response to actions based on intentional decisions made on the part of the grower. The decision-making process is complex and impacted by factors that are not easily defined and vary from grower to grower, and even field to field. Economics of weed manage- ment practices, company marketing programs, options for profitable crops or cropping systems, ability to access financing, availability of equipment and labor, contractual arrangements, reliability of the source of recommendations on weed management tools, and personal experiences of the grower are but a few of the many factors that come into play.

Third: Growers at times have a sense of hopelessness or feeling of a lack of control over their ability to prevent or mitigate the spread of herbicide resistance that underscores the severity of the problem. Often growers also feel like it does not matter what they do, since their neighbors' actions will cause them to have the problem regardless of what actions they take on their own farm.

Fourth: Growers historically have been able to rely on the development of new herbicide technologies to combat resistance, which provides a false sense of security that a silver bullet will always come along. This is not an unreasonable conclusion, since in almost every instance of herbicide resistance evolution, a new silver bullet did in fact appear. However, that paradigm is changing dramatically, since there has not been a new MOA developed in more than 30 years.

Fifth: In particular, with the glyphosate resistance issue, growers have enlarged their operations dramatically because of the ease of weed control. Reverting to more complicated weed control programs is viewed as impossible without changing their entire farming operation: hiring more labor, buying more equipment, or farming fewer acres. Grower response at times when considering BMPs for herbicide resistance management are typically "I just can't do that." Nonchemical weed control programs (e.g., tillage) not only require more labor and equipment, but can also have dramatic impacts on conservation tillage programs and USDA compliance. Landlords and/or financial lenders may require specific crops and cropping systems to be used, or even require specific weed management regimes, in order to maximize their return on investment. Many studies have shown that, while herbicide resistance management practices are almost always economically beneficial over the long term, they are often more expensive in the first year or two of implementation. In the same vein, a substantial portion of cropland is rented, and renters often

Shaw: Wicked nature of herbicide resistance • 555 


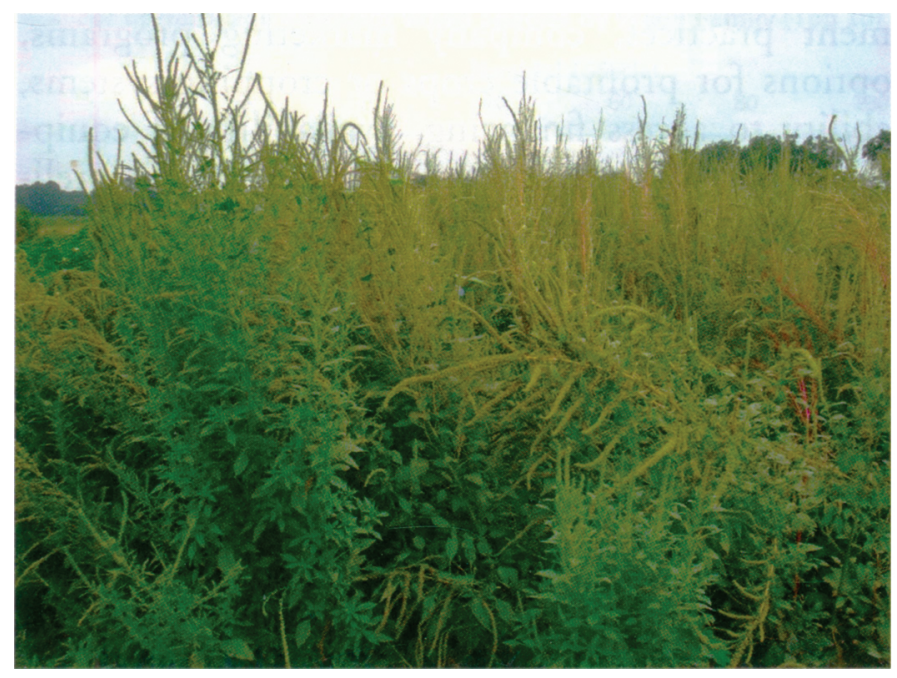

Figure 6. Palmer amaranth following multiple applications of glyphosate in a cotton field in George. Photo courtesy Stanley Culpepper.

will choose to maximize short-term profits, since there is no guarantee of keeping rented land to be able to realize long-term benefits.

Finally, changing cropping systems and crop rotations requires additional expertise, purchasing more or different equipment, etc. In a situation in which time and financial resource demands are already overwhelming, adding "one more thing" is simply too much.

These are but a few myriad factors coming into play when considering changes in weed control programs to incorporate stewardship plans for herbicide resistance management.

Albert Einstein has been widely quoted (and sometimes misquoted) in defining insanity as "doing the same thing over and over again and expecting a different result." This concept is no better portrayed than with the current situation we are in with herbicide resistance. Continuing to take the same approaches, doing "more of the same" surely will have a predictable outcome, and result in more scenes like that shown in Figures 6 and 7. An editorial in the journal Nature recently highlighted the failure to adequately address the role of the social sciences in research across all hard science disciplines, noting "if you want to deliver for society, you need to support a capacity to understand that society" (Anonymous 2014). With this in mind, the Herbicide Resistance Education Committee of the WSSA has partnered with rural sociologists, agricultural economists, the National Academy of Science, and crop consultants to take a

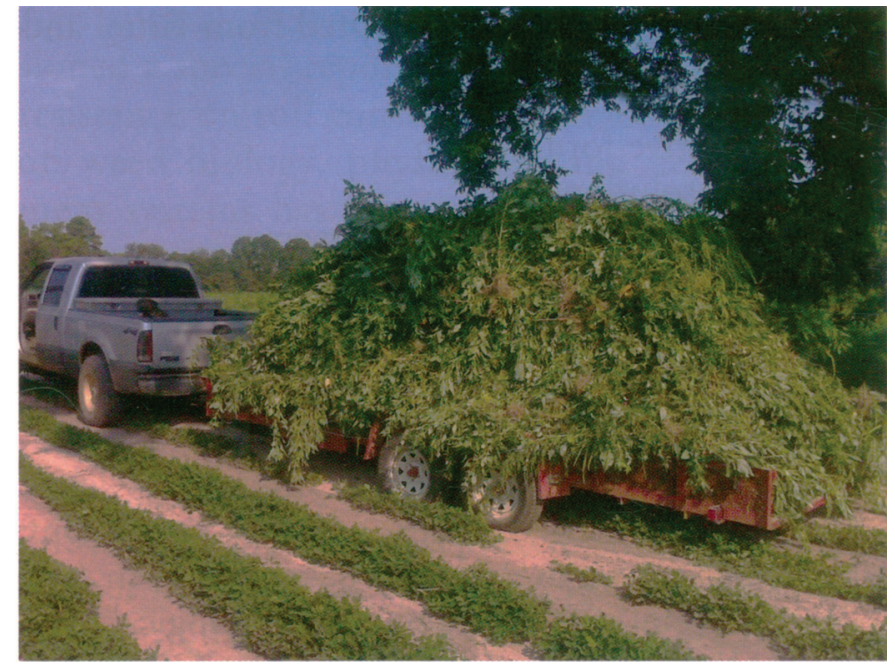

Figure 7. Palmer amaranth removed by hand weeding and loaded on a trailer to haul away from a North Carolina peanut field to avoid replenishment of the soil seedbank. Photo courtesy Alan York.

careful look at what can be done "differently." The result was the second Herbicide Resistance Summit, conducted September 2014. Recommendations coming out of the second Herbicide Resistance Summit were:

- Increase awareness that everyone engaged with agriculture has a role in managing herbicide resistance and accountability for that role.

- Develop a herbicide resistance management certification program for weed management decision makers and advisors.

- Reduce regulatory barriers to herbicide resistance management; e.g., conservation compliance.

- Establish prototypical, community-based areawide herbicide resistance management programs for specific threats; e.g., Palmer amaranth in Iowa.

- Communicate the effect of herbicide resistance management on short- and long-term farm profitability.

- Implement programs for scouting and controlling weed escapes.

- Provide short-term financial incentives to reduce the cost of developing and implementing field-byfield herbicide resistance management plans.

- Market/promote consistent and scientifically sound herbicide resistance management programs.

- Incentivize innovation in nonchemical weed management practices. 
Videos of the presentations from the second Herbicide Resistance Summit, along with slide sets and other materials, can be viewed at http://wssa. net/weed/resistance-summit-ii/. All of these recommendations from the second Herbicide Resistance Summit were targeting the wicked nature of the problem of herbicide resistance, and were developed in the context of the human, socio-economic dimensions of herbicide resistance.

Federal agencies have begun to fulfill their roles in responding to the wicked nature of herbicide resistance. For example, the Environmental Protection Agency in fall 2014 announced that a part of the label requirement for the Enlist Duo registration would be a requirement for a herbicide resistance stewardship plan. This groundbreaking change highlights the agencies commitment to proactively addressing resistance evolution. In response to this, WSSA, the American Society of Agronomy, and the National Association of Independent Crop Consultants is considering how to develop training and certification programs for herbicide resistance stewardship plan development.

Secretary of Agriculture Tom Vilsack announced on October 15, 2014 (http://www.usda.gov/wps/ portal/usda/usdamediafb? contentid $=2014 / 10 / 0227$. $\mathrm{xml} \&$ printable=true\&contentidonly=true) that USDA would be taking several steps to address herbicide resistant weed management, including:

- USDA's Natural Resource Conservation Service (NRCS) is offering financial assistance under its Environmental Quality Incentives Program (EQIP) for herbicide resistant weed control practices that utilize Integrated Pest Management plans and practices.

- NRCS has developed a new program within its Conservation Innovation Grants (CIG) Program, requesting proposals for innovative conservation systems that address herbicide resistant weeds.

- USDA's APHIS will actively promote use of BMPs in design protocols for regulated authorized releases of genetically engineered (GE) crops and will include recommendations for BMPs with the authorization of field trials of herbicideresistant crops.

- USDA is partnering with the WSSA and is providing funds to develop education and outreach materials for various stakeholders on managing herbicide-resistant weeds.

In addition, the National Academy of Science conducted a scoping meeting immediately after the
Second Herbicide Resistance Summit to begin the process of defining a future study on pest resistance management.

These steps by government agencies are positive, in that they are challenging old paradigms and causing the entire weed management community to reconsider approaches that can spur more effective and sustainable weed management practices. However, these are only a few of the steps that will be necessary if we are to appropriately address this issue. Other articles in this special issue address the roles of incentives and regulations, educational programs, community-based approaches, economic aspects of implementing herbicide resistance BMPs, the need for further diversification of these BMPs, and a call to action for everyone involved. Herbicide resistance will only be managed through the combined efforts of all parties (e.g., industry, university, government, retailers/dealers, consultants). Everyone involved must understand the role each individual can play, and work collectively to achieve the outcomes we all desire if we are to overcome this wicked problem. All involved must also hold each other accountable for actions. We must not only think differently; rather, we must act differently.

\section{Acknowledgments}

The planning committee for the Second Herbicide Resistance Summit played a critical role in the planning and execution of the Summit, and in the development of the topics that resulted in the articles in this special issue. Committee members included Amy Asmus, Michael Barrett, Harold Coble, David Ervin, George Frisvold, Les Glasgow, Michael Horak, Terry Hurley, Raymond Jussaume, Micheal Owen, Jill Schroeder, John Soteres, and Blaine Viator.

\section{Literature Cited}

Anonymous (2014) Time for the social sciences. Nature 517:5

Bradshaw LD, Padgette SD, Kimball SL, Wells BH (1997) Perspectives on glyphosate resistance. Weed Technol 11:189-198

Churchman CS (1967) Wicked problems. Management Science 14:B141-B142.

Heap I (2015) The International Survey of Herbicide Resistant Weeds. http://www.weedscience.com. Accessed February 25, 2015

Shaw: Wicked nature of herbicide resistance - 557 
Norsworthy JK, Ward SM, Shaw DR, Llewellyn RS, Nichols RL, Webster TM, Bradley KW, Frisvold G, Powles SB, Burgos NR, Witt WW, Barrett M (2012) Reducing the risks of herbicide resistance: best management practices and recommendations. Weed Sci 60 (Special issue):31-62

Rittel H, Webber M (1973) Dilemmas in general theory of planning. Policy Sci 4:155-169

Switzer CM (1957) The existence of 2,4-D resistant wild carrot. Proceedings North Central Weed Science Society $9: 75-77$
Vencill WK, Nichols RL, Webster TM, Soteres JK, MallorySmith C, Burgos NR, Johnson WC, McClelland MR (2012) Herbicide resistance: toward an understanding of resistance development and the impact of herbicideresistant crops. Weed Sci 60 (Special issue):2-30

Received March 5, 2015, and approved February 3, 2016. Associate Editor for this paper: Sarah Ward, Colorado State University. 